\title{
Cross-Linguistic Influence in Chinese Learners of Two Foreign Languages While Studying Abroad in Spain
}

\author{
Wenxiao Zhao \\ University of Jinan \\ sfl_zhaowx@ujn.edu.cn
}

\begin{abstract}
Studies in the area of cross-linguistic influence (CLI) have attracted the focus of multi-linguistic learners. However, little research on CLI deals with Asian learners, particularly Chinese-speaker with knowledge of two or more foreign languages. The present study explores CLI in L1 Chinese learners with both English (L2) and Spanish (L3) as foreign languages who are studying in Madrid, a Spanish-speaking community; their studies coincided with data collection. English learners were instructed to speak for analysis purposes, with the following aims: (i) to observe the most frequent category (functional transfer, code-switching, borrowing and coinage) in the CLI instances; (ii) to determine the source language of CLI; (iii) to investigate whether CLI factors, including language distance, L2 status, proficiency and recency of use, intervene in the appearance of CLI instances in the participants.

Data was gathered from 16 female Chinese students at Complutense University of Madrid (UCM). These were master students aged 22 to 26, who visited Spain for more than 5 months when they participated in the present study. The instrument used was an English semi-structured interview. Results primarily reveal that (a) borrowing is the most prevalent category, accounting for $70 \%$ of the CLI instances; (b) Spanish is the main source language of CLI while Chinese plays a functional role in the transfer process; (c) language distance proves to be the strongest predictor of CLI.
\end{abstract}

Keywords: cross-linguistic influence (CLI), L3 Spanish, borrowing, functional transfer, language distance 


\section{Introduction}

Studies in the area of cross-linguistic influence (CLI) have attracted the focus of multi-linguistic learners (e.g. Hammarberg, 2001). The CLI forms employed for two foreign languages by learners are distinct from learning a unique L2. Clyne claimed that additional languages may complicate the process (Clyne, 1997). However, there is little analysis of multilingual learners compared to the myriad of studies dealing with learners of a single foreign language. There is even less data for L1 Chinese multilingual learners.

The present study intends to explore the CLI phenomenon in Chinese learners with two foreign languages, L2 English and L3 Spanish. The sample comprises sixteen Chinese students with knowledge of English and Spanish, who study in Spain at the time of data collection. We examined students' English oral production with the aim of exploring the CLI patterns and the source of transfer. The study begins by reviewing definitions of L3 acquisition used in different CLI studies. It also evaluates recent results in this field. Factors involved in CLI are also introduced in this section to provide a theoretical foundation for the study. Section 3 introduces the design of the study, including the context of the study, the instruments employed for data collection, the procedure and how CLI instances were coded. Section 4 presents the results of the study with tables and CLI instances appearing in the data. Section 5 interprets CLI patterns of Chinese students by comparing these results with previous studies. Several factors were taken into consideration in analyzing the CLI condition, including typology, L2 status, recency, proficiency as well as social factors. The final section concludes as follows. It summarizes major findings of the study and makes suggestions for future research.

\section{Literature Review}

\subsection{The Concept of $L 3$ Acquisition}

For several decades, most studies on cross-linguistic Influence (CLI) have focused on the influence of the native language (L1) on a second language (L2). For some time, third language acquisition (TLA) has been viewed as a branch of second language acquisition. Nonetheless, after many former studies (e.g. Vildomec, 1963; Ringbom, 1987), this research area has developed (e.g. Cenoz, Hufeisen, \& Jessner, 2001; Hammarberg, 2001). TLA has been explored under the guise of L3 studies, and treated as a different learning process than SLA. When treated as a different learning process, TLA can account for a number of acquisition phenomena, which first language acquisition (FLA) and SLA cannot (Flynn, Foley \& Vinnitskaya, 2004).

One must distinguish L2 and L3 by acquisition process. Only native languages are shown to exert a cross-linguistic influence. Yet, L3 involves at least an additional source language (SL). In essence, prior knowledge of a non-native language is a factor that must be controlled. An added source language will involve more complex mental processes during learning. In conclusion, prior knowledge of a non-native language is a variable that must be controlled. 
Another source language will involve more complex mental functions during language learning. As Kallenbach (1996, 1998) notes in his studies, L3 learners generally possess richer language knowledge and more learning strategies than L2 learners. As learners of an additional language, they must put a great deal of effort in suppressing influence from former language systems. Thus, Thomas (1992) suggested that multilinguals are superior to bilinguals and monolinguals with regard to analytical ability. Their analytic traits are used to discern how linguistic systems are structured. This is performed with the aim of promoting L3 acquisition.

Yet, compared to the limited learning routes of L2 (learned after L1 or at the same time as the L1), third language acquisition can take a variety of routes. Cenoz (2000) held that at least four acquisition orders can be examined:

a) Learners may acquire the three languages simultaneously;

b) Learners may acquire the three languages consecutively;

c) Learners may learn L2 and L3 simultaneously after L1 learning;

d) Learners may learn L1 and L2 simultaneously before L3 acquisition.

Logically, different learning routes will result in different learning effects. Hence, this invites a multitude of research areas. The complexity of L3 acquisition should be distinguished from L2 acquisition. This calls for a clarified description of this new phenomenon. As the name suggests, some may prioritize first and second languages more than third languages. In this sense, L3 signifies the order of language acquisition (third in this case). Thus, the concept of L4, L5, etc. will be treated as languages learned in sequence. As Hammarberg (2001) claimed, it is common in studies to apply the term L3 for any non-native language acquired after L2, i.e., from the third language and onwards. For example, in De Angelis \& Selinker (2001)'s case study of two adult multilinguals' interlanguage transfer, the interlanguages of the subjects were listed in order of acquisition but not of fluency.

In some studies, L3 may refer to a language acquired after a second language. Hence, third language is usually marked as "L3". For convenience, both L4, or L5 languages will be termed L3. Further, Fouser (2001) adopted the notation " $L>=3$ " to include all languages learned beyond the L3 without adding another numerical term, such as L4 or L5. This definition will clearly distinguish between L2 and L3. Hammarberg (2001:22) also suggested an operational definition. L3 is defined as a new language being acquired, while L2 refers to a non-native language. In his study, L3 is used to substitute the most recent language. One may examine third languages from another perspective. First languages were learned from birth or in the critical period, aiding the ease of language acquisition. If this concept is applied to L2 and L3, this will explain the development of language fluency. L3 signifies the third proficient language in one's full language scheme or the second in one's non-native language system. This implies that linguistically, L2 comes more naturally than L3, rendering speakers more comfortable with its use. In the present study, L3 is treated as language number three. That is to say, the two foreign languages of the participants in our study 
are listed in order of acquisition. As a result, English is L2 and Spanish is L3 for our L1 Chinese participants.

\subsection{Recent Results in TLA}

In recent years, the area of L3 has investigated different language features from distinct perspectives. First of all, vocabulary constitutes one aspect that has been investigated the most (e.g. Cenoz, Hufeisen, \& Jessner, 2003; Ringbom, 2001). Lexical transfer is particularly obvious in learners' production, either in oral or in written form. There exist mainly two types of CLI-based lexical transfer: adapted transfer and non-adapted transfer. Adapted transfer suggests that lexical items from a background language (either L1 or L2) is adapted to the target language (TL); it has been divided into the categories lexical invention, lexical substitution and calque following Dewaele (1998)'s framework. Non-adapted transfer is viewed as codeswitches, i.e., utterances of L1 or L2 inserted into TL without modifications. According to the different functions, Hammarberg (2001) identified seven types of non-adapted switches: edit, meta comment, meta frame, explicit elicit, implicit elicit, non-elicit, wipp.

Ringbom (1987) claimed that some types of transfer involve a more complex linguistic process than others. The author hypothesized that transfer of form usually takes place in the early stages of acquisition, whereas transfer of meaning requires higher levels of proficiency of TL. Bardel \& Lindqvist (2007) confirmed that codeswitches had been used in the initial stage of Italian acquisition by a learner with low proficiency. However, as the learner's L2 is Spanish - a language which is typologically near to TL, the results of this study should be carefully interpreted. Celaya (2006)'s longitudinal study discovered a considerable decline of non-standard forms in written production in three time periods. However, the author reported that the calque type is different from the other types because it involves a distinct cognitive process.

De Angelis (2005a) claimed that not all function words are perceived as equally transferable to the target language. CLI is particularly visible in lexical transfer because the traces of non-target forms are usually easy to recognize. However, it is still an area far from being fully explored. For example, there exist few studies investigating advanced learners. Furthermore, different L1 and L2 could also lead to different forms of lexical transfer.

Compared to the relatively mature investigation of vocabulary, CLI at the syntactic level is a younger research field. Jaensch (2011) examined gender and number concord in adjectival inflection in L3 German, which neither appears in the participants' L1 Japanese nor in their L2 English. A comparison was made among three groups according to different L2 levels of proficiency across three data-elicited tasks. Results did not support either the Cumulative Enhancement Model (Flynn et al., 2004) or the L2 Transfer proposal (Falk \& Bardel, 2011) due to the absence of the same form in the L1 or L2. However, the variation between task and number by L3 German learners could be explained by Distributed Morphology (Halle \& Marantz, 
1993). Falk \& Bardel (2010) tested the placement of object pronouns in both main and subordinate clauses in German as L3, which constitutes another important grammatical item in German. One group had English as L1 and French as L2 and another group consisted of French native speakers with L2 English. The significant difference in various L3 items between the two groups provided evidence for the L2 status factor. Rothman \& Jennifer (2010) compared data from English native speakers of L2 Spanish beginners of acquiring L3 French and L3 Italian relating to properties of the Null-Subject Parameter. The authors provided data of English learners of L2 French and L2 Italian. The results also verified the importance of the L2 status. However, proofs for typological proximity were also provided in this thesis.

In conclusion, a number of syntactic studies conducted in recent years have given birth to two famous models: Cumulative Enhancement Model (CEM), Typological Primacy Model (TPM). We will discuss the two models in 2.3.6.

\subsection{Factors Involved in TLA}

The discussion of TLA has involved a number of factors that determine source languages that will play an important role in L3 transfer. Some of the most important factors include language distance, L2 status, recency of use, and proficiency of source languages and TL, which constitute factors specifically explain the mental process of multilinguals. In contrast, some other factors, e.g., age of onset, could explain both native and non-native CLI. Also, sometimes interactions between factors or combinations of several factors will be the reason for a specific CLI phenomenon to occur. In the subsections that follow, special attention will be paid to the effects of language distance, L2 status, recency of use, proficiency, order of, which are all factors that will be benefit to the interpretation of the results of the present research.

\subsubsection{Language Distance}

Language distance (also called typology) refers to the objective distance between source languages and TL. That is to say, a linguist can formally identify language distance between languages and language families (De Angelis, 2007). In TLA, it can be specifically identified as similarities between the SL and the TL. A number of investigations have verified the importance of the language distance factor (Ahukanna, Lund, \& Gentile, 1981; Möhle, 1989; Ringbom, 1987).

Further distinction relates to the notion of perceived language distance. According to Kellerman (1983), psychotypology refers to the perception of the distance among languages by learners. It indicates learners' subjective perception of relationship between languages and language families, corresponding to the objective distance or not, and it is not obligatory to match the objective linguistic similarity. For example, learners whose native languages are non Indo-European normally select other Indo-European languages they know as source language to transfer in the L3 acquisition process. Some studies have investigated such kind of CLI, in which the researchers explored a Hindi or Chinese speaker with L2 English who acquires German (Chandrasekhar, 1978; Vogel, 1992). The results demonstrated that L2 English, an Indo-European language, is the main source of another Indo-European 
language - German during the learning process for both Hindi and Chinese learners. Cenoz (2001) explored the SL of transfer in groups of L1 Spanish learners, L1 Basque learners, or Spanish-Basque bilinguals learning L3 English. The results also verified the presence of psychotypology because Spanish is the main source of L3 transfer by learners instead of Basque - a non Indo-European language. Furthermore, the participants with L1 Basque tend to transfer more from Spanish to English compared to other two groups.

There are also a number of L3 studies that examined CLI from languages that are close to L3. For example, Ringbom (1987) argued that the English L3 subjects were more influenced by Swedish than Finish since both English and Swedish are Germanic languages, while Finish is not. De Angelis (2005a, 2005b), Bardel (2006) demonstrated that a Romance L2 could be easily transferred to another Romance L3.

\subsubsection{L2 Status}

The role of L2 status has received particular attention recently. It was originally proposed by Williams \& Hammarberg (1998) in their case study, in which a tendency to activate L2 rather than L1 by the multilingual subject in the process of L3 acquisition had been identified. As a result, "learner's intention to suppress L1 and to rely more on L2 as source language to acquire L3" was defined by Hammarberg (2001: 37) as L2 status factor.

Recent research by Falk \& Bardel (2010) compared a L1 English, L2 French groups to a L1 French, L2 English group examining their L3 German object placement. As object placement is pre-verbal in French and post-verbal in English, the test of TL whose object placement varies between pre-verbal in the sub-clause and post-verbal in the main clause could well examine the L2 status factor in the learning process of German. The results manifested that the two groups behave differently as to grammaticality judgment/ correction task (GJCT) of object placement due to L2 status influence, which proved the strong role that the L2 status factor played in the process of L3 acquisition.

L2 status can also been termed as "foreign language effect" according to Meisel (1983). The reason for relying more on L2 other than L1 is that L3 learners normally need a SL as supplier to support their L3 production if they intend to speak a "foreign" language. Therefore, when they have difficulty in speaking L3 proficiently, they resort to L2 because it is a "foreign" language at least. In this condition, L2 become the main source of transfer since they "sound like foreign". Bardel \& Falk (2007) have suggested that adult language learners classify their languages according to sociolinguistic and cognitive differences. Consequently, the L2 status factor could be viewed as the predominant factor that mitigates the importance of those social and cognitive factors which are valuable in the process of L1 and L2 acquisition, such as age, aptitude, attitude, metalinguistic awareness or learning strategies in the process of L3 acquisition. 


\subsubsection{Proficiency}

Proficiency in both TL and in SL is another factor to consider in the L3 transfer process. With respect to TL proficiency, most researchers maintain that CLI occurs more easily at the initial stage of L3 learning, considering the imbalance between learners' weak L3 proficiency and their need to communicate and fill knowledge gaps in L3 production (e.g. Navés, Miralpeix, \& Celaya, 2005). Odlin (1989) pointed that at this stage most cases of transfer are negative due to the learner's limited linguistic ability in the TL. In contrast, high proficiency L3 learners would be capable of making use of the appropriate language source to transfer to the target language, thus making positive transfer work.

As to proficiency in the SL, we know that there exists a threshold level that makes positive transfer to occur. However, we hardly know where this threshold level is. Although transfer has been shown to occur not only from successful L2 learners (e.g. Williams \& Hammarberg, 1998), but also from L2s that learners do not know very well (e.g. De Angelis, 1999), the characteristics of transfer differs with L2 proficiency levels. For example, transfer of meaning is more likely to be applied by learners with high proficiency while low proficiency learners tend to rely more on transfer of form. This notion has been proved by many researchers (De Angelis, 1999; Celaya, 2006).

Proficiency level in the TL and SL is an important factor for learners to make the transfer decision. However, we have only very limited understanding of how it affects the L3 acquisition process due to the lack of studies that analyze proficiency level in the SL as an essential variable. The present study aims at investigating in depth the influence of proficiency factor in transfer.

\subsubsection{Recency of Use}

The notion of recency refers to the hypothesis that foreign language will be more easily to access to if it has been used recently by learners. Thus, the most recent foreign language will be more likely to become the SL of transfer. The participant in Hammarberg (2001) began to learn Swedish after six years of residence in Germany. L2 German in this case is the he most recently used language for the subject. The results manifested that German constitutes the main linguistic source of transfer. Although we could not neglect other factors like learner's good metalinguistic ability and the effect of typology, the recency factor does play an important role in this case.

Sometimes learners may claim that they have not used a language for a long time and thus that it will not influence their L3 learning process. However, this claim is not usually true. For example, one participant in Herwig's study (2001) had difficulty in controlling the influence from Dutch - a language that is not used recently. This Irish L1 learner of German reported that his knowledge of Dutch to be quite weak compared to other languages. Interestingly, CLI from the weak language seems considerably strong. 
While languages not used for a long time can still affect TL, the L2 languages that have been used recently or are being used now by learners have more powerful influence in L3 acquisition due to its activeness. Learners may found it hard to suppress the negative influence from these active foreign languages as they are stored in the same region in one's brain. More investigations are needed to explore the effect of this special factor involved in L3 acquisition.

\subsubsection{Order of Acquisition}

Order of acquisition has been argued to refer to the types and amount of transfer that will occur during the L3 learning process. We will briefly describe the bestknown study on this factor by Dewaele (1998). In this study, participants who had L2 French and L3 English were compared to those whose L2 were English and L3 were French. Through a series of test, Dewaele found that speakers of French as L2 were more reliant on L1 Dutch, while those of French as L3 were more reliant on L2 English. With the same language combination in two groups, the only explanation of the difference is the effect of order of acquisition. That is to say, the order in which a language is acquired will determine the CLI features in the production of L3.

\subsubsection{Combinations of All the Factors: Two Models}

Although many factors involved in L3 acquisition have been studied, it still remains unclear how these factors interact between two or more previously acquired languages and L3. As a result, some scholars have proposed several models to explain the source and the main factor determining L3 transfer.

Flynn et al. (2004) proposed the Cumulative Enhancement Model (CEM) for L3 learning in 2004. In this study, the authors worked with three groups of learners who had L1 Kazakh and L2 Russian, L1 Spanish and L1 Japanese respectively. The target structure was restrictive relative clauses (also called Complementizer Phrase). English, Spanish and Russian are head-initial in Complementizer Phrase (CP) structure; in contrast, Kazakh and Japanese are head-final in CP. The results showed that the third group (L1 Japanese) provided different English production from the other two groups. The authors argued that the third group had no previous knowledge on head-initial CP, while the other two groups had already acquired a language, either in L1 or L2, with the head-initial CP. That is to say, the learners in L1 Japanese group did not have transfer source for head-initial CP and therefore they could not perform correctly in this structure.

As a result, Flynn et al. (2004) claimed that all background languages that the learners know, including L1 or L2s, have effects, either positive or neutral on the acquisition of L3. That is to say, all the languages that learners knew can act as language sources for L3 acquisition. This claim thus is concluded by author to CEM, which proposed that "language acquisition has a scaffolding effect in the sense that any prior language can either enhance subsequent language acquisition or remain neutral" (Flynn et al., 2004: 12). 
Based on CEM theory, Rothman (2010) collected data from beginners of L3 Brazilian Portugueses with L1 English/L2 Spanish and L1 Spanish/L2 English to examine similarities and differences in their L3 acquisition process of noun-raising (a rule that exists in all languages except English). The results demonstrated that learners from both groups had successfully mastered the rule. Consequently, the author maintained typology constituted the main factor that determined the transfer source. Finally, the author made some modifications of the former $C E M$ and formed a new Typological Primacy Model (TPM) for multilingual transfer. TPM termed typology as the most predictive factor in determining L3 transfer from either L1 or L2. The author concluded that "according to economy of acquisition, the most proximate language becomes the source for transfer independently of the language being an L1 or an L2" (Rothman, 2010: 125).

To sum up, all the factors have its effect on CLI. However, it is still remain unknown which factor or the combination of more than two factors would be the best predictor. Those models have provided us some possibilities to explain the factor effects. Future research should integrate all these models to test hypothesis and possibly to form new models to better illustrate the factor effects.

\subsection{Research Questions}

In view of the research reviewed above, the present study aims at analyzing:

a) Which is the source language of CLI in L1 Chinese learners of English? What types of CLI do these participants produce?

b) Which factors intervene in the appearance of CLI in the participants?

Do any transfer patterns appear in the data?

c) Is the type of word (open-class words and closed-system items) affected by CLI?

\section{Method}

\subsection{Context}

Data was collected in the philology faculty of Complutense University of Madrid (hereafter, UCM). This site was chosen according to the following rationale. Firstly, Madrid, the capital of Spain, is fraught with cultural, artistic, and intellectual activities. Overseas students enrolled in Madrid's local universities rank first among all the Spanish cities. Several important universities are stationed in the Madrid Autonomous Region.

Second, Madrid is a monolingual community in Spain. However, there are many other cities in Spain where only Castellano is spoken. Many people, in bilingual regions, can perfectly distinguish between Castellano and Galego, Catalán or Euskara. However, there is little or no influence of languages other than Spanish in Madrid. As a result, many international students study Spanish in Madrid to aid the acquisition of "pure" Spanish. 
At UCM, the last three years have witnessed a rise in matriculation of Chinese students in certain faculties. Within the philology department, Chinese undergraduate and master students have occupied nearly $30 \%$ in all the programmes, official or alternative. Furthermore, trend continually increases every year. A large quantity of Spanish majored students who had finished their undergraduate courses in a Chinese university arrive at Madrid to continue their postgraduate studies.

In the academic year 2011-2012, the number of Chinese enrolled in the master programme Spanish as second language had reached forty. We chose sixteen subjects enrolled in this programme at random from those who volunteered to participate. A purposive sample was used, as subjects were chosen on the basis of their characteristics. Among these subjects, randomized sampling was performed, as each person, in this subset, had an equal chance of being selected for this study.

\subsection{Participants}

The participants for the present study are sixteen female Chinese students. They aged from 22 to 26 . The average age of participants is 23.5 years old. The whole sample comprised students in the master programme Spanish as second language at UCM. Our statistics reported that half of the participants had spent five or six months in Spain. Over 10\% of them had lived in Spain for one year and the rest $40 \%$ more than one year (See Figure 1). This study was carried out in accordance with the recommendations from the Committees on Human Research Protection of University of Jinan (China) and Complutense University of Madrid (Spain). The protocol was approved by both universities. All subjects gave written informed consent in accordance with the Declaration of Helsinki.

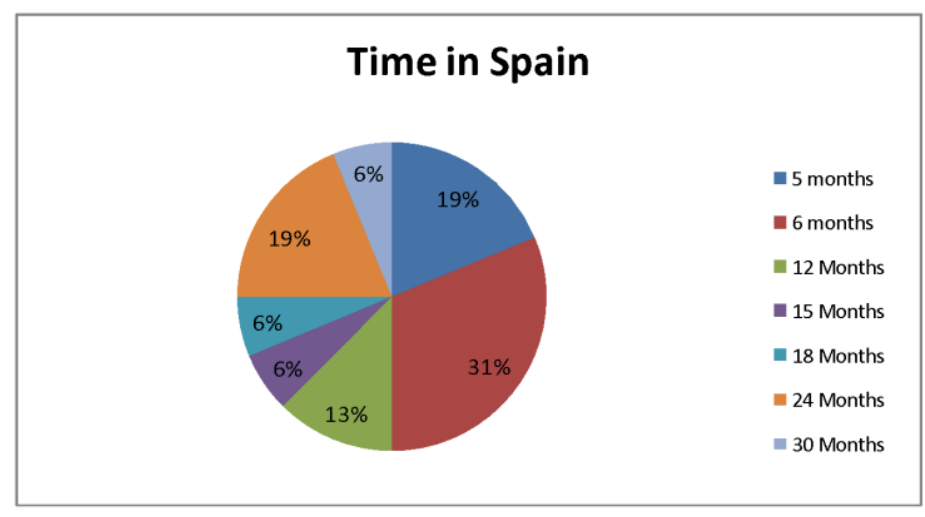

Figure 1: Length of time in Spain

All the participants claimed that they had majored in Spanish during their college years (One studied in a university of Cuba (No.1) and the rest fifteen subjects were in different universities of China). Five of those participants who had studied Spanish athome environment had opportunities to go to a Spanish-speaking country during their college years. Two (No.2, No.9) had once been sent to Cuba as an exchange student for nearly one year; one (No.10) stayed six months in Spain also for exchange purpose; one subject(No.4) had been in Spain for only two months attending a 
summer language course; and the last one (No.12) had only less-than-one-month traveling experience in Spain.

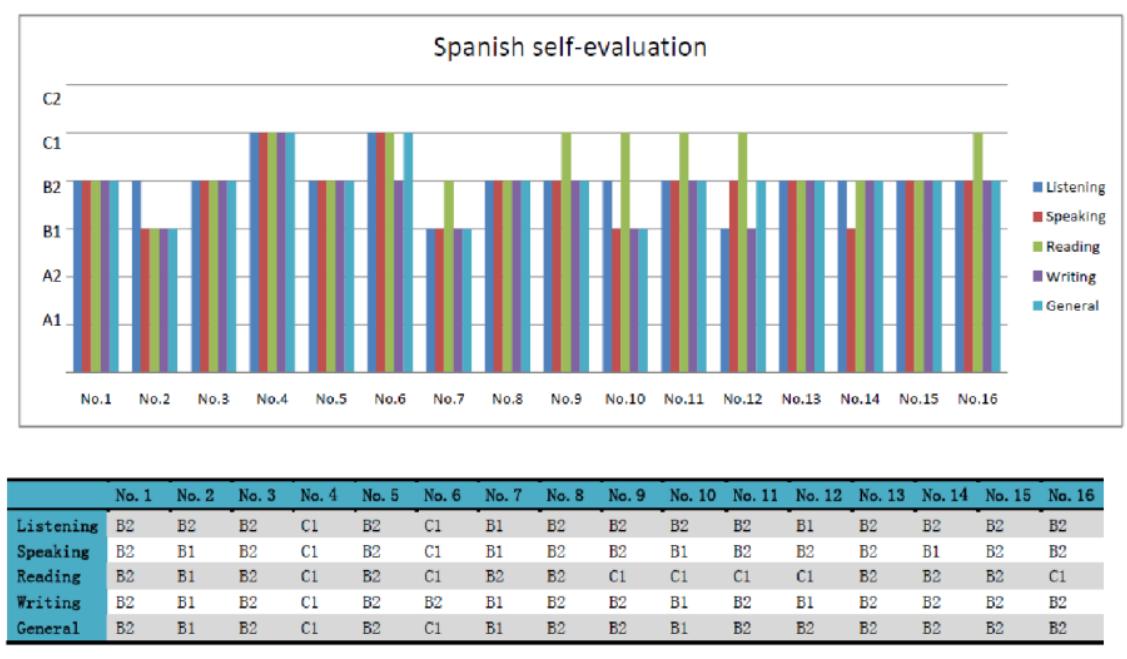

Figure 2: Self-evaluation of Spanish proficiency

All the participants started to learn Spanish in their first college year (At the age 18 or 19). Thanks to the four year major study, the average proficiency level of these subjects in Spanish is relatively high, between B2 to C1 according to the European framework based on their self-evaluation (See Figure 2). The majority (over 60\%) of the subjects possessed B2 level in all four aspects of Spanish skills as well as general proficiency level. Furthermore, close to half of the participants considered their reading skills to be $\mathrm{C} 1$.

Referring to English, the starting age of participants varied from five to fifteen (See Figure 3). However, a large part of the sample (seven of all the sixteen participants) started learning English at the age of ten following the normal Chinese education policy.

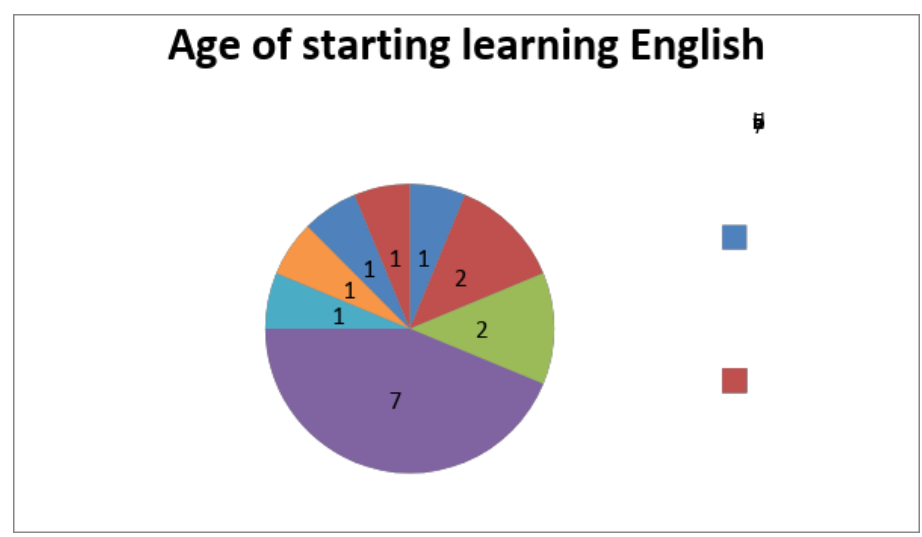

Figure 3: Age of starting learning English (10 years old-SEVEN; 6 years oldTWO; 8 years old-TWO; 5, 12, 13, 14, 15 years old-ONE respectively) 


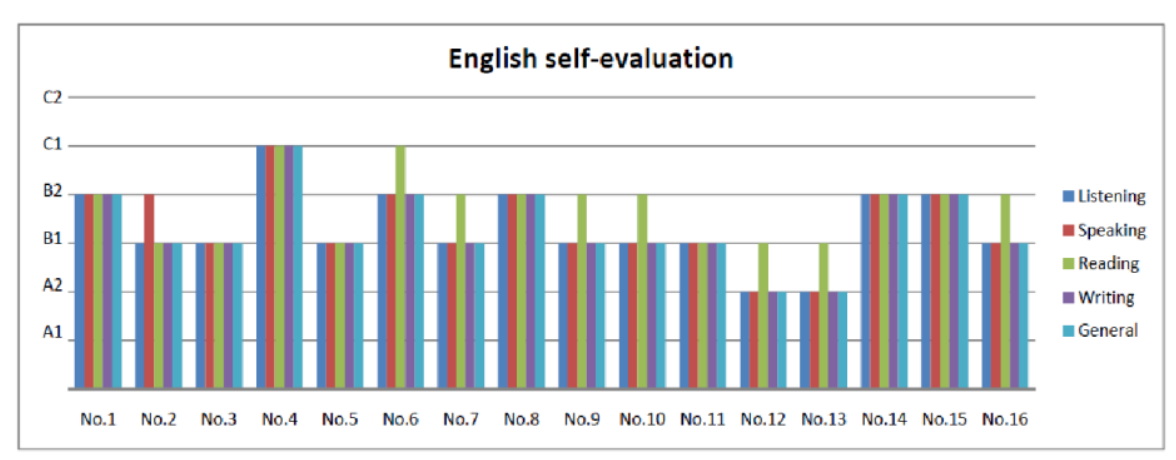

\begin{tabular}{lllllllllllllllll}
\hline & No. 1 & No. 2 & No. 3 & No. 4 & No. 5 & No. 6 & No. 7 & No. 8 & No. 9 & No. 10 & No. 11 & No. 12 & No. 13 & No. 14 & No. 15 & No. 16 \\
\hline Listening & B2 & B1 & B1 & C1 & B1 & B2 & B1 & B2 & B1 & B1 & B1 & A2 & A2 & B2 & B2 & B1 \\
Speaking & B2 & B2 & B1 & C1 & B1 & B2 & B1 & B2 & B1 & B1 & B1 & A2 & A2 & B2 & B2 & B1 \\
Reading & B2 & B1 & B1 & C1 & B1 & C1 & B2 & B2 & B2 & B2 & B1 & B1 & B1 & B2 & B2 & B2 \\
Writing & B2 & B1 & B1 & C1 & B1 & B2 & B1 & B2 & B1 & B1 & B1 & A2 & A2 & B2 & B2 & B1 \\
General & B2 & B1 & B1 & C1 & B1 & B2 & B1 & B2 & B1 & B1 & B1 & A2 & A2 & B2 & B2 & B1 \\
\hline
\end{tabular}

Figure 4: Self-evaluation of English proficiency

As a result, all the subjects have studied English for at least nine years as a foreign language from secondary school to university, usually four 45-minute classes a week. The majority of those students had taken one or two English proficiency test during their college year. CET-4 or CET-6 (College English Test, Band 4 or 6) is the test that nearly all the participants had participated, because it constitutes the test that is compulsory to pass with the goal of graduating from university. TOEFL and IELTS, as international language proficiency tests, had been put in the second rank after the CET tests. However, due to the foreign language status and limited input (only two participants had a short stay no more than one month in an English speaking country before the period of data (No.4, No.14)), their English proficiency level did not correspond so much with the long learning time, which varied from A2 to C1 according to the European framework (See Figure 4). Close to half of the subjects evaluated themselves to be B1 with regard to English listening, speaking and writing. As to English reading, half of the participants reported that they possessed B2 level in this skill, being higher than the other three. However, the results indicated that the general English level of half of the participants was B1 when taking into considerations their overall abilities of all four skills.

Furthermore, they all claimed that their Spanish proficiency to be higher or at least equal to their English level (See Figure 5). With respect to additional languages, only two students told that they had knowledge of other languages besides Spanish and English. One subject (No.15) reported her French level to be BASIC (A1 according to the European framework). And the other one (No.16) is a KoreanChinese bilingual. As a result, the influence of additional languages should be taken into consideration in case of No. 15 and No.16. 


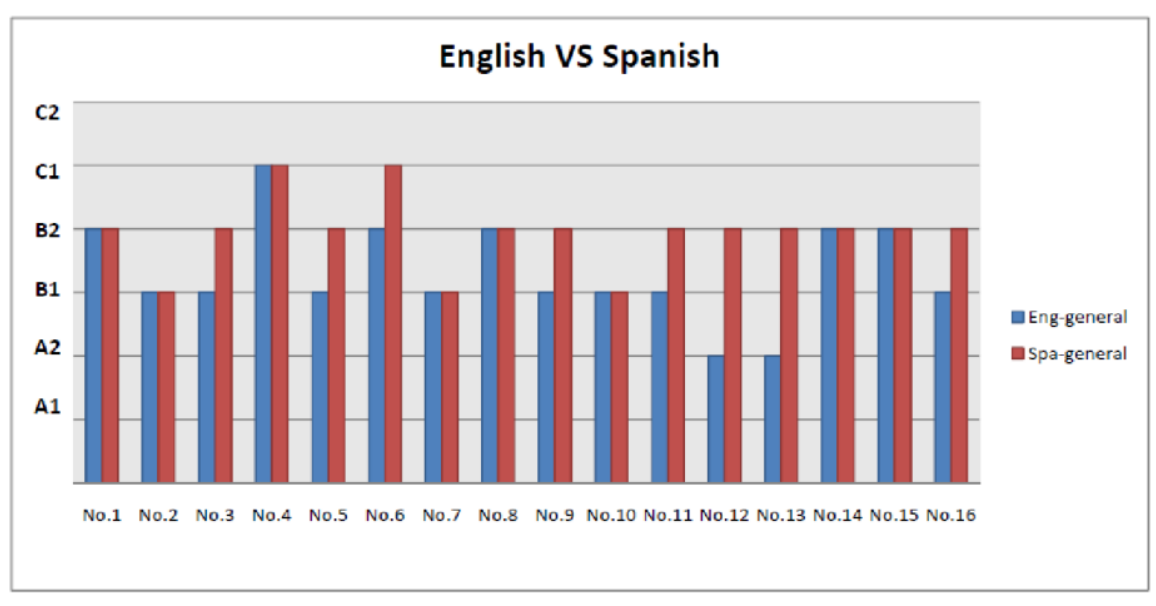

Figure 5: The overall comparison of English and Spanish proficiency

\subsection{Ethics Procedure}

Ethics approval and consent procedures were required for this study. These procedures were employed to facilitate the study. All studies involving human participants must be performed by the World Medical Association's Standards (Declaration of Helsinki). These studies must adhere to their structural guidelines and acquire the approval of an ethics community. Informed consent, which is also required, is both a form and a process as well.

Prior to this study, the researcher performed the informed consent procedures. Information, regarding the study, was provided to the subjects, to acquire their voluntary participation. A dialogue was also exchanged regarding procedures, purpose, alternative, and risks of the study. Consent is an ongoing process, as subjects have the right to withdraw at any time from the study (Shahnazarian, Hagemann, Aburto \& Rose, 2013). Another factor considered was the setting in which consent was acquired. This setting will impact the emotional and psychosocial health of the subject.

Subjects were provided enough information to make a voluntary decision, regarding their participation. For this purpose, subjects were informed of the following. They were informed of the study's purpose, procedures, and participation alternatives. Risks and benefits of the study were also disclosed to the subject. Subjects were informed the duration of the study, and were offered emergency contact information. Finally, they were offered statements affirming the study was voluntary and refusal to participate would not incur consequences. Finally, subjects were provided a right to confidentiality statement.

\subsection{Instrument}

\subsubsection{Oral Interview}

CLI data were elicited through a 5- to 10- minute interview in English. The interview schedule (See in Appendix 1) comprised two modules (module A and module B) of English questions. Each module included ten general questions on 
students' childhood, daily life, or hobby, etc. It is worth noticing that the questions included in module B are all parallel questions of module A. For example, the first question in module $\mathrm{A}$ is to ask participants' favourite place in their hometown; similarly, the first question in module B is on their perception of famous things in their hometown. The participants were randomly divided into two groups. In the first group, the researcher made a face-to-face interview with one participant. In the second group, the researcher asked two students to form a small subgroup and they should alternatively ask and answer questions to one another. The two modules of questions included in the interview schedule were used to organize the two parts of the interview. In the first group, the question schedule was used as a guide for the researcher to elicit data. That is to say, the type of interview is semi-structured. In this case, the interviewer was able to choose questions from either module A or module B according to the situation. In contrast, in the second group, participant A should asked all the questions from module A to participant B and answered all the questions of participants B from module B and vice versa. Structured interview was applied in the second group.

As our goal was to examine the cross-linguistic influence in participants' oral production, complexity, accuracy and fluency (CAF) of the data will not be reported in the present study. Therefore, we tried to include relatively simple questions in the schedule so that the participants would feel at ease during the interview and thus produced more CLI data. Also, the contents of the participants' answers to the questions were not of our interests. That is to say, attention was paid rather to "how" they speak than "what" they speak.

\subsubsection{Background Questionnaire}

A general language background questionnaire was designed to obtain participants' basic information on language learning experience. The questionnaire consisted of a two-page form in Chinese. A parallel Spanish version of the same questionnaire was also available for participants during the period of data collection. Therefore, four pages were distributed to participants. However, subjects attending the present study were asked to complete only two pages of either Chinese version or Spanish version with language they preferred - in Chinese or Spanish.

The questionnaire comprised two parts. In Part 1, subjects were asked to provide their basic information, such as their age, gender, major, etc. Part 2 constituted the essential part of the questionnaire, in which surveyed subjects' learning experience of both English and Spanish. They should make a self-evaluation on language proficiency of both English and Spanish in listening, speaking, reading and writing. Also, the general levels of these two languages were elicited by means of selfevaluation. The Part 2 also provided other information on students' learning experience including their onset age, the types of proficiency test they had participated, their stay-abroad experience, etc. Supplementary information on learners' additional languages besides English and Spanish were included in Part 3. In this part, participants were asked to specify their knowledge of other languages. In addition, learners' aims of learning foreign languages were clarified in Part 3. 
It should be noted that at first the questionnaire were designed only to obtain participants' background information. However, after examining the information of all the completed questionnaires, we found that some data, like participants' proficiency levels, would benefit our analysis. As a result, the questionnaire was employed as the main instrument of the study.

\subsection{Procedure}

The first step of the present study was to implement the questionnaire survey. Before delivering the questionnaires to the participants, we piloted the questionnaire with one student that would not be included in the study with the aim of determining how long it would take to answer the questionnaire, if the contents were clear and whether the format was adequate. The questionnaire was administered to the participants in the classroom of their university in Madrid. The teacher of the class spared us 10 minutes to do the survey before the lesson started. Students were asked to fill out only one version of the questionnaire, either the Chinese one or the Spanish one. Detailed explanations were given to students in Chinese. And also, the students were able to ask questions to the researcher in Chinese at any time during completing the questionnaire. Finally, sixteen students submitted the questionnaire.

After finishing collecting the questionnaires, the next step is to determine the main instrument (s) of data collection. Two types of instruments were chosen as candidates of data collection: a picture description task and an interview. In order to determine the better instrument that would easily elicit more instances of CLI, a pilot study were carried out before the real data collection process.

One Chinese student who had a similar language background with the sample attended the pilot study. The student was asked to complete the two tasks in sequence, first the picture description and then the interview. It took him only three minutes to finish narrating the story in the picture. And then the researcher began to ask him questions following the interview schedule. The whole process lasted five minutes. After the process of data collection, data from the pilot study were examined. Little CLI instances were found in the first picture description task, while the interview had elicited more transfer phenomena. We considered that the picture task may be too easy for the participant and also the lack of interaction in the picture description task made it more convenient for the participant to avoid using languages other than the TL. Therefore, we decided to choose the interview as the main means of data collection.

As long as the instrument was decided, we contacted another time with the former participants. One participant was missing in the final stage of data collection due to personal reasons. Finally, sixteen subjects participated in the interview. The interview was held in the same classroom where the questionnaire survey was completed. We arranged each participant or group a concrete time to come to the classroom to do the interview. As mentioned in 3.3.2, the participants were randomly divided into two groups. The first half of the students was interviewed by the researcher; while the other half of the students interviewed each other within their 
small subgroup consisted of two students with the presence of the researcher. In the second condition, participant A should ask one question from module A to participant $\mathrm{B}$, and the participant $\mathrm{B}$ should respond to the question of participant A. After answering participant A's first question, they changed turns. Participant B began to ask the parallel question from module B to participant A and participant A should give answers. The whole process finished after both of the two participants asked all the questions from her own module and responded to all the questions from her partner's module. All the interview excerpts were recorded and transcribed (See examples of transcription in Appendix 2). After the interview, we carried out another session with one participant to get further information about her CLI characteristics and learning styles.

\subsection{Analysis}

The literature review section above has reported a number of different types of CLI. In the present study, we mainly followed methods of categorization of Cenoz (2001) and Hammarberg (2001) but with some adjustments according to the special traits of our data. As a result, four types of cross-linguistic influence were identified in the present study. These types of non-target terms are described and illustrated in what follows.

\section{$\underline{\text { Sentence level }}$}

1. Functional transfer: sentences or terms produced in Spanish or Chinese with the aim of getting help from the researcher to produce the target form. It includes four of the seven types of switches defined by Hammarberg (2001):

a) Meta-comment: participants' comments on the communicative situation or on the instrument itself, e.g.

¿Ya está no? ('That's all, right?’)

¿Qué más? ('What's more?')

b) Meta-frame: language switches with a question frame, which usually accompanies longer strings with the aim of asking about the target form to the researcher, e.g.

Keep in touch with Shenme yisi? ('What')

c) Explicit elicit: target language elicitation strategies with a meta-frame, e.g.

guli zenme shuo? ('How do you say the word encouragement in English?')

d) Implicit elicit: target language elicitation strategies with a rising intonation without frame, e.g.

Yaogun? ('Rock music') 


\section{Zhentan? ('Detective')}

2. Code-switching: whole sentence produced in Spanish or Chinese without asking for help to the researcher, e.g.

Es que no me gusta ('Because I don't like it')

Wo tongnian mei shenme shiqing. ('There is nothing special in my childhood.')

\section{$\underline{\text { Word level }}$}

3. Borrowing: words or terms (but not whole sentences) produced in Spanish or Chinese without intention to adapt them to the target language. The borrowing words will be classified as belonging to open-class words (nouns, verbs, adjectives, adverbs) or closed-system items (determiners, pronouns, conjunctions, prepositions, auxiliary verbs including be/have/do, enumerators, interjections - greetings and conversational 'lubricants' such as 'no way', 'yes', 'OK', 'sure' etc.).

Open-class borrowing, e.g.:

And China I think we will be more abierto ('open') to the world

Because it's a work very útil ('useful')

Closed-system borrowing, e.g.:

I think it's very helpful $y$ ('and') I should learn more

MiUniversidad@s ('my university') is in ...

4. Coinage: words or terms produced in Spanish or Chinese with some phonological or morphological adaptation (Poulisse, 1990), e.g.:

I'm not going to be a espanish ('Spanish') teacher

\section{Results}

Table 1 shows the frequency of types of CLI and their distribution in Chinese and Spanish as source languages of influence. The total number of transferred terms is 106. It can be observed that Spanish is the main source language of cross-linguistic influence. $89 \%$ transferred terms are from Spanish. Furthermore, the participants use a greater number of Spanish terms than Chinese in code-switching, e.g. Aunque es una cuidad mиy pequeña, las personas viven mejor que otras cuidades de Anhui 'Although it is just a small city, people here have a better life than other cities in Anhui Province', borrowing, e.g. She likes see the korean telenovela 'television series', and coinage, e.g. I think the best to study Spanish is talk con@s los@s nativo@s 'native speakers'. Chinese is the complementary source of TL which explains the rest $11 \%$ of transferred terms. The only category in which Chinese transferred terms are slightly more than Spanish is functional transfer. As a result, we 
may conclude that Chinese mainly acts as a functional tool in the process of CLI. However, the participants rely more on Spanish in those direct forms of transfer, such as borrowing or code-switching. It can also be observed that terms of function transfer (12 instances) and code-switching (16 instances) are very similar. However, there only exist four instances of coinage in the corpus and all of them are adapted Spanish words.

\begin{tabular}{|l|l|l|l|}
\hline Category & N & Chinese (\%) & Spanish (\%) \\
\hline Functional Transfer & 12 & $7(58 \%)$ & $5(42 \%)$ \\
\hline Code-switching & 16 & $4(25 \%)$ & $12(75 \%)$ \\
\hline Borrowing & 74 & $1(1 \%)$ & $73(99 \%)$ \\
\hline Coinage & 4 & $0(0 \%)$ & $4(100 \%)$ \\
\hline Total & 106 & $12(11 \%)$ & $94(89 \%)$ \\
\hline
\end{tabular}

Table 1 Frequency and Frequency distribution (\%) of CLI in Chinese and Spanish

The data also indicate that the participants produced substantially more Spanish borrowing than the other categories in the corpus. The total number of borrowing is 74 , which occupies close to $70 \%$ of the whole 106 CLI instances. In order to examine this type of compensatory strategy in detail, all the borrowing terms were divided into two groups: open-class words and closed-system items. The results of the comparisons of the two groups are presented in Table 2.

\begin{tabular}{|l|l|l|l|}
\hline \multicolumn{1}{|c|}{ Groups } & $\mathbf{n}(\boldsymbol{\%})$ & Chinese & Spanish \\
\hline Open-class words & $33(45 \%)$ & 1 & 32 \\
\hline Closed-system items & $41(55 \%)$ & 0 & 41 \\
\hline Total & 74 & 1 & 73 \\
\hline
\end{tabular}

Table 2 Open-class words and Closed-system items

The results indicate that the participants borrow more closed-system items (33 instances), e.g. If I travel, only una 'a' week, than open-class words (41 instances), e.g. The most important factor is responsabilidad 'responsibility'. Furthermore, nearly all the borrowing words except one are from Spanish. The only Chinese borrowing word belongs to open-class words group, as in It's just like chaofan 'fried rice'.

The following Table 3 shows the subcategories and their distribution of functional transfer. This CLI type constitutes the only type that the number of Chinese terms is larger than the number of Spanish transfers. As it could be found in Table 3, the meta-comment switches are always in Spanish, e.g. ¿Ya está no? 'That's all, right?'; in contrast, in the other three categories, the learners resort to Chinese switches, e.g. Keep in touch with Shenme yisi 'What'. The data indicate that the learners were more likely to give comments on the communicative situations or the 
instrument in Spanish - a foreign language. However, when they intended to ask some questions to the researcher, especially when they need help to produce a specific target term, they would like to directly use Chinese switches to ask for help.

\begin{tabular}{|l|l|l|l|}
\hline Categories & $\mathbf{N}$ & Chinese (\%) & Spanish \\
\hline Meta-comment & 5 & $0(0 \%)$ & $5(100 \%)$ \\
\hline Meta-frame & 2 & $2(100 \%)$ & $0(0 \%)$ \\
\hline Explicit elicit & 3 & $3(100 \%)$ & $0(0 \%)$ \\
\hline Implicit elicit & 2 & $2(100 \%)$ & $0(0 \%)$ \\
\hline Total & 12 & $7(58 \%)$ & $5(42 \%)$ \\
\hline
\end{tabular}

Table 3 Frequency of CLI in Functional transfer

\begin{tabular}{|l|l|}
\hline Language(s) & No. of participants who transferred \\
\hline Chinese & 0 \\
\hline Spanish & 9 \\
\hline Chinese \& Spanish & 6 \\
\hline Total & 15 \\
\hline
\end{tabular}

Table 4 Number of participants who transfer Chinese, Spanish or both languages into English

\begin{tabular}{|l|l|l|l|}
\hline No. of CLI terms & No. of participants & Percentage & Cumulative Percentage \\
\hline 0 & 1 & 6.3 & 6.3 \\
\hline 1 & 3 & 18.8 & 25.0 \\
\hline 2 & 1 & 6.3 & 31.3 \\
\hline 3 & 2 & 12.5 & 43.8 \\
\hline 4 & 2 & 12.5 & 56.3 \\
\hline 8 & 1 & 6.3 & 62.5 \\
\hline 9 & 2 & 12.5 & 75.0 \\
\hline 13 & 1 & 6.3 & 81.3 \\
\hline 16 & 1 & 6.3 & 87.5 \\
\hline 18 & 1 & 6.3 & 93.8 \\
\hline 38 & 1 & 6.3 & 100.0 \\
\hline Total & 16 & 100.0 & \\
\hline
\end{tabular}

Table 5 Distribution of participants who produced different numbers of CLI terms 
The results in Table 4 indicate the number of participants who had used transfer strategies in their English production. There are fifteen participants who resorted to CLI strategies during the data collection and only one participant did not produce any terms other than target language English. Among these fifteen learners who had transfers, nine of them only chose Spanish as source language, while six learners produced both Chinese and Spanish switches. There were no participants who had only used Chinese as compensatory language when speaking English. That is to say, Spanish is the source language for all the fifteen participants who transferred.

Table 5 indicates that four participants produced more than ten CLI terms, which occupies $25 \%$ of the whole sample as we can see in table 5. And also there exists one participant who produced 38 transferred terms during the interview. The results show that some participants have been greatly affected by cross-linguistic influence when speaking English.

\section{Discussion}

This study examines cross-linguistic trends on Chinese learners versed in two foreign languages; English and Spanish. The results revealed the participants evoked both Chinese and Spanish when producing EFL. However, L1 Chinese and L3 Spanish were triggered in distinct situations. Transferred Spanish terms composed 89\% of the sample, while Chinese terms composed $11 \%$. In essence, Spanish is the primary source of language transfer in English. In accordance with Hammarberg (2001)'s theory, Spanish plays a prominent role in production of English in this study. The participants attempted to modify their English sentences with Spanish switches or reformulated Spanish words with the aim of compensating the lack of active English words. In contrast, learners' L1 Chinese served as a functional tool in the process of language learning. The only transfer category in which Chinese has a stronger effect than Spanish is functional transfer. According to Williams \& Hammarberg (1998), Chinese plays an instrumental role in CLI. The participants were willing to switch to L1 when commenting on the following: When they intended to initiate conversations or desired to elicit target forms from the researcher. This coincides with previous research findings by Hammarberg (2001).

Spanish was selected as a supplier in this study. Hence, the CLI forms coincided with unique factors, and a composite of factors as well. Firstly, close to $90 \%$ of the transferred terms in Spanish confirmed the predominant rule of language distance. As Spanish and English are both Indo-European languages, Spanish is typologically closer to English than Chinese. As a result, this study observed a stronger influence from Spanish than from Chinese. The current findings reinforce the notion of language distance. This implies that typology is one of the most salient factors in determining CLI patterns (Cenoz, 2001; Möhle, 1989).

Secondly, most transferred Spanish terms in the data may be seen as the prime influence of the L2 status factor. The participants' willingness to use Spanish as supplier may stem from their intention to speak a foreign" language. With a Chinese mother tongue, the subjects may mentally perceive that Chinese is "incorrect". In 
essence, they used Spanish, a foreign language, instead. In this context, Spanish triggers language transfer, as it "sounds foreign". These findings confirm prior studies on the L2 status factor or foreign language effect (Falk \& Bardel, 2010; Hammarberg, 2001).

The stronger presence of Spanish may be attributed to the recency factor. All participants studied in Spain and were pursuing a masters degree in a Spanishspeaking community, during the period of data collection. In this condition, Spanish was particularly active for learners. For instance, prior to data collection, they may have conversed with Spanish people or read a newspaper in Spanish. In this case, the recency factor plays a prominent role. However, it can be confirmed that recency is a potential factor affecting CLI process (Hammarberg, 2001; Herwig, 2001).

The data also showed the participants used substantially more borrowings than the other types of CLI strategies. Their proficiency levels in English may have been lower than that in Spanish. As described by Celaya (2006), "borrowing" emerges most often at T1 (200 hs), persists at T2 (416 hs), but decreases at T3 (726 hs). This verified the types and modes of transfer were shaped by participants' proficiency level and instruction time. As a "transfer of form" category, borrowing occurred in low proficiency learners' production (De Angelis, 1999; Celaya, 2006). However, our study failed to offer support for this finding. The study participants labeled themselves as "B1"- lower intermediate level- in English. As a result, we determine the borrowing words in the corpus stem from proficiency of learners' English and Spanish. Although not English beginners, the subjects' high Spanish proficiency (B2 in general) affected the transfer types and ways. However, more studies are needed to better discern the effect of this kind in combination with the "proficiency" factor.

Another interesting finding of borrowing is participants borrowed more openclass words (33 instances) than closed-system items (41 instances). Our classification of open-class and closed-system items corresponded to Cenoz (2001)'s function and content words to a certain degree. Nevertheless, our results conflicted with Cenoz (2001)'s findings. Cenoz (2001) found more content than functional words in the study. In contrast, this study's participants borrowed more closed-system items than open-class words. One reason this pattern differs from Cenoz's findings (2001) are the high rates of closed- system items. This includes si 'yes in Spanish' and $y$ 'and in Spanish', etc. Among the 41 occurrences of closed-system items, there were 8 si 'yes in Spanish' and $11 y$ 'and in Spanish'. The transfers of these words were particularly obvious in the corpus. These words belonged to the closed-system items, and increased this category's number of instances. Considering the small sample size, we could not conclude our findings negate Cenoz (2001)'s claim. Navés et al. (2005) found a similar percentage of transferred content words and transferred function items in young low-proficient learners. Through Navés et al. (2005)'s study, we could see that age is an important factor affecting the distribution of the function and content items in a specific group. As the participants in our study differ from those of Cenoz (2001) and Navés et al. (2005) in age (adults vs. young students), it is not surprising that the results are not identical. Future explorations with a larger sample size and different age groups will highlight this phenomenon in depth. 
Finally, $25 \%$ of the participants produced more than 10 CLI terms in the interview. The results reveal some participants have been greatly affected by CLI in speaking English. To better comprehend this phenomenon, we consulted with most participants two days after data collection. We inquired about their language learning experiences with English and Spanish. One subject, for instance, noted that before her Spanish studies, she possessed a better English level. In her first year of university, their teachers informed them to cease their English studies-as this would conflict with their Spanish learning. Then she interrupted her English studies for nearly two years. As a result, when she intends to speak English, she utters Spanish words. Her experience supplied more insights on CLI. Occasionally, a learners' belief and their social environments may impact the quantity and type of transfer.

\section{Conclusion}

The present study sheds light on the process of CLI in L1 Chinese participants with two foreign languages. Generally speaking, the study confirms all learners' languages influenced their oral production of EFL. However, each language served a different role in determining their transfer patterns. In our study, L3 Spanish has a major supplier role in speaking English, while L1 Chinese plays an instrumental role. These results confirm previous findings on language distance in multilingual acquisition. Typology has been proved to be a strong predictor of cross-linguistic influence. However, it can also be seen that L2 status and recency of use have effects on CLI. As a result, CLI patterns observed in our data can be viewed as the results of a combination of several CLI factors.

Another finding is that participants produced considerably more instances of borrowing than of other CLI types. We interpret this result as the effects of the participants' proficiency level in both Spanish and English. Our data also indicate that learners borrowing more Spanish closed-system items than open-class words. Although this result does not correspond to previous studies (Cenoz, 2001; Navés et al., 2005), it does not contradict previous research.

In general, the present study provides insights on Chinese multilingual' transfer patterns and factors in determining the source language. However, it is important to take into account that this study was carried out in a specific setting where all the participants were studying Spanish in a Spanish-speaking community. Thus, the results cannot be generalised without taking these specific contextual variables into account. Furthermore, the present findings are based on a relatively small corpus. CLI data with a bigger sample would provide further information on CLI in the future. Finally, only the Chinese learners' oral production in English was tested in the present study. CLI patterns of written data may also provide different perspectives on CLI. Also, future research may not only examine participants' English but also their Spanish. If possible, these studies may make a comparison of Spanish and English production to illustrate the CLI in Chinese learners of two foreign languages. 
Another route of research may incorporate the concept of synaptic transfer. For instance, there is a distinction in the placement of sentence negation in L2 and L3 languages. Furthermore, a qualitative difference exists in acquisition between L2 and L3 languages. (Bardel \& Falk, 2007) Some contend L2 modulates vocabulary learning in L3. However, some researchers disagree the effects of L2 may apply to subsequent languages. Furthermore, L2 influence may not apply to the simple, syntactic aspects of grammar for L3 acquisition (Bardel \& Falk, 2007). Hakansson et al. proposed the developmentally moderated transfer hypothesis (DMTH) (Bardel \& Falk, 2007). According to this theory, no syntactic transfer occurs from L2 to L3 (Bardel \& Falk, 2007). However, new evidence suggest syntactic transfer occurs more smoothly from L2 to L3, than from L1 to L3 (Bardel \& Falk, 2007). Therefore, future studies should examine the transfer of syntax structure to subsequent language. Native languages may or may not have a stronger effect in transferring language systems such as these. Furthermore, a strong typological relationship may exist between L2 and L3 than initially presumed.

\section{References}

Ahukanna, J. G. W., N. Lund, and R. J. Gentile. 1981. "Inter- and intra-lingual interference effects in learning a third language". Modern Language Journal 65: 281287.

Bardel, C. 2006. "La connaissance d'une langue étrangère romane favorise-t-elle l'acquisition d'une autre langue romane? Influences translinguistiques dans la syntaxe d'une L3 ». Acquisition et Interaction en Langue Etrangère 24: 149-180.

Bardel, C., and C. Falk. 2007. "The role of the second language in third language acquisition. The case of Germanic syntax". Second Language Research. 23. 4: 459484.

Bardel, C., and C. Lindqvist. 2007. "The role of proficiency and psychotypology in lexical crosslinguistic influence. A study of a multilingual learner of Italian L3". Atti del $6^{\circ}$ Congresso Internazionale dell'AssociazioneItaliana di Linguistica Applicata, Napoli. 2006.

Celaya, M. L. 2006. "Lexical transfer and L2 proficiency: A longitudinal analysis of EFL written production”. In A. S. Alcaraz, C. P. Soto, and M.C.G. Zunido. (Eds.). Paper presented at AEDEAN Conference, Jaén. CD format.

Cenoz, J. 2000. "Research on multilingual acquisition". In J. Cenoz, and U. Jessner. (Eds.). English in Europe: The Acquisition of a Third Language. Clevedon: Multilingual Matters, 39-53.

Cenoz, J. 2001. "The effect of linguistic distance, L2 status and age on cross- 
linguistic influence in third language acquisition". In J. Cenoz, and U. Jessner (Eds.). English in Europe: The Acquisition of a Third Language. Clevedon: Multilingual Matters, 8-20

Cenoz, J., B. Hufeisen, and U. Jessner. 2001. "Third language acquisition in the school context". International Journal of Bilingual Education and Bilingualism, 4 (special issue).

Cenoz, J., B. Hufeisen, and U. Jessner. 2003. "Why investigate the multilingual lexicon?" In J. Cenoz, B. Hufeisen, and U. Jessner (Eds.). The multilingual Lexicon. Dordrecht: Kluwer Academic Publishers.

Chandrasekhar, A. 1978. "Base language". International Review of Applied Linguistics. 16. 1: 62-65.

Clyne, M. 1997. "Some of the things trilinguals do". The International Journal of Bilingualism.1: 95-116.

De Angelis, G. 1999. "Interlanguage transfer and multiple language acquisition: a case study". Paper presented at TESOL 1999, New York City.

De Angelis, G. 2005a. "Interlanguage transfer of function words". Language learning. 55. 3: 379-414.

De Angelis, G. 2005b. "Multilingualism and non-native lexical transfer: an identification problem”. International Journal of Multilingualism. 2. 1: 1-25.

De Angelis, G. 2007. Third or Additional Language Acquisition. Clevedon: Multilingual Matters.

De Angelis, G., and L. Selinker. 2001. "Interlanguage transfer and competing linguistic systems in the multilingual mind". In J. Cenoz, B. Hufeisen, an U. Jessner. (Eds.), Cross-Linguistic Influence in Third Language Acquisition: Psycholinguistic Perspectives. Clevedon: Multilingual Matters, 42-68.

Dewaele, J. M. 1998. "Lexical inventions: French Interlanguage as L2 versus L3". Applied Linguistics. 19. 4: 471-491.

Falk, Y., and C. Bardel. 2010. "The study of the role of the background languages in third language acquisition. The state of the art". IRAL 48: 185-219.

Falk, Y., and C. Bardel. 2011. "Object pronouns in German L3 syntax: Evidence for the L2 status factor". Second Language Research 27: 59.

Flynn, S., C. Foley, and I. Vinnistskaya. 2004. "The cumulative enhancement model of language acquisition: comparing adults' and children's patterns of development in first, second and third language acquisition of relative clauses". International Journal of Multilingualism. 1. 1: 3-16. 
Fouser, R. J. 2001. "Too close for comfort? Sociolinguistic transfer from Japanese into Korean as an L $\geq 3$ ". In J. Cenoz and U. Jessner. (Eds.). English in Europe: The Acquisition of a Third Language. Clevedon: Multilingual Matters, 149-169.

Halle, M., and A. Marantz. 1993. "Distributed morphology and the pieces of inflection". In K. Hale, and S. J. Keyser (Eds.). The View from Building 20: Essays in Linguistics in Honor of Sylvain Bromberger. Cambridge: MIT Press, 111-176.

Hammarberg, B. 2001. "Roles of L1 and L2 in L3 production and acquisition". In J. Cenoz, B. Hufeisen and U. Jessner. (Eds.). Cross-Linguistic Influence in Third Language Acquisition: Psycholinguistic Perspectives. Clevedon: Multilingual Matters, 21-41.

Herwig, A. 2001. "Plurilingual lexical organisation". In: J. Cenoz, B. Hufeisen and U. Jessner. (Eds.). Cross-Linguistic Influence in Third Language Acquisition: Psycholinguistic Perspectives. Clevedon: Multilingual Matters, 115-137.

Jaensch, C. 2011. "L3 acquisition of German adjectival inflection: A generative account". Second Language Research 27: 83.

Kallenbach, C. 1996. Subjective Theorien- was Schüler und Schülerinnen über Fremdsprechenlernen denken. Tübingen: Narr.

Kallenbach, C. 1998. "Da weiss ich schon, was auf mich zukommt, L3-Spezifika aus Schülersicht". In B. Hufeisen and B. Lindemann (Eds.). Tertiärsprache: Theorien, Modelle, Methoden. Tübingen: Stauffenburg, 47-57.

Kellerman, E. 1983. "Now you see it. now you don't”. In S. Gass and L. Selinker (Eds.). Language Transfer in Language Learning. Rowley: Newbury House, 47-57.

Meisel, J. 1983. "Transfer as a second language strategy". Language and Communication. 3. 1: 11-46.

Möhle, D. 1989. "Multilingual interaction in foreign language production”. In W. H. Dechert and M. Raupach. (Eds.) Interlingual Processes. Tübingen: Stauffenburg, 179194.

Navés, T., I. Miralpeix, and M. L. Celaya 2005. "Who transfer more... and what? Cross-linguistic influence in relation to school grade and language dominance in EFL". International Journal of Multilingualism. 2. 2: 113-134.

Odlin, T. 1989. Language Transfer. Cross-Linguistic Influence in Language Learning. Cambridge: CUP.

Poulisse, N. 1990. The Use of Compensatory Strategies by Dutch Learners of English. Dordrecht: Foris Publications.

Ringbom, H. 1987. The Role of the First Language in Foreign Language Learning. Clevedon: Multilingual Matters. 
Ringbom, H. 2001. "Lexical transfer in L3-production". In J. Cenoz, B. Hufeisen and U. Jessner. (Eds.). Cross-Linguistic Influence in Third Language Acquisition: Psycholinguistic Perspectives. Clevedon: Multilingual Matters, 59-68.

Rothman, J. 2010. "L3 syntactic transfer selectivity and typological determinacy: The typological primacy model”. Second Language Research 27: 107-127.

Rothman, J., and C. A. Jennifer, 2010. "What variables condition syntactic transfer? A look at the L3 initial state". Second Language Research 26: 189.

Shahnazarian, D., Hagemann, J., Aburto, M., \& Rose, S. 2013. Informed consent in human subjects research. Office for the Protection of Research Subjects (OPRS), University of Southern California.

Thomas, J. 1992. "Metalinguistic awareness in second and third-language learning". In R. J. Harris (Eds.). Cognitive Processing in Bilinguals. Amsterdam: North-Holland, 531-545.

Vildomec, V. 1963. Multilingualism. Leyden: A. W. Sythoff.

Vogel, T. 1992. "English und Deutsch gibt es immer Krieg, Sprachverarbeitungsprozesse beim Erwerb des Deutschen als Drittsprache“. Zielsprache Deutsch. 23. 2: 95-99.

Williams, S., and B. Hammarberg. 1998. "Language switches in L3 production: implications for a polyglot speaking model”. Applied Linguistics. 19. 3: 295-333.

\section{Appendix 1. Sample Interview Questions}

\begin{tabular}{l} 
Candidate A \\
1. Tell me about your hometown. What's your favorite thing or place in \\
your hometown? \\
2. Can you tell me something about your childhood? Did you have friends \\
in that period? Do you still maintain your friendship with him or her? \\
3. What would you like to do in the future? Do you want to be a Spanish \\
teacher? What about your future plan, to stay here or to go back to China? \\
\hline
\end{tabular}

Candidate B
1. Where were you born? A small city or a big city? What is famous about your
hometown?
2. Tell me about your undergraduate university. Do you like it? Which teacher do
you like best? Do you keep in touch with each other?
3. Which are the most popular jobs among Spanish major students? What would
be your ideal job? Tell me your experience.

\section{Appendix 2. Sample Transcription of Interviews}

Recording No.: V120423004.WMA; Subject: 14; Type: interview

*INV: Where were you born?*SUB14: In China. *INV: Tell me something about your hometown.*SUB14: My hometown is in Zhejiang. And it's a small town of 
Zhejiang. *INV: What is famous about your hometown?*SUB14: Famous? Bamboo?*INV: Very good. Some famous place?*SUB14: No. Not have place.*INV: Ok. Tell me about your university in China. *SUB14: It's in Changchun. *INV: Do you like it?*SUB14: Yes. It's very serious.*INV: Which teacher do you like best?*SUB14: A teacher from Spain.Se@s 1lama@ Ana. Muy@s amable@s.*INV: Do you still keep in touch with your teacher?*SUB14: No. *INV: Ok. What would you like to do in the teacher. To be a Spanish teacher?*SUB14: In the future? I don't like to be a Spanish teacher. I'd like to commercial?*INV: Good. You'd like to stay here or go back to China?*SUB14: Go back to China. *INV: Go back to China. Ok. Do you think learning a foreign language is important? *SUB14: Yes, it's very important. *INV: Why?*SUB14: To communicate with people around countries because I like to do a commercial in the future. *INV: Yes. Do you think Madrid is a noisy city? *SUB14: Yes a very noisy city. A little.*INV: Would you like to study in other Spanish cities? *SUB14: No. I like to go back and graduated from here.*INV: Ok. Are you bored if you stay at home for a long time? Is it boring?*SUB14: Yes. It's boring for staying at home more than half a month. *INV: So you will go traveling. *SUB14: Yeah. Traveling. *INV: What is your favorite Spanish food? *SUB14: Spanish food.*INV: You don't like Spanish food no?*SUB14: I haven't eat any delicious food.We always eat menú@sdel@s día@s. No@es@muy@good.*INV: Tell me something about your hobbies.*SUB14: Hobbies. I like to play piano. I learnt it when I was in \#prima primary school. *INV: So you like music?*SUB14: I can't say. Solo@s only I like to play the instrument. *INV: So you like classic music?*SUB14: Classic music yes. *INV: So the last question. What do you think is a perfect boyfriend? *SUB14: Perfect boyfriend? The most important is he [//] his [/] his personality. And he must be kind and take care of me. And ambitious. *INV: Oh ambitious?*SUB14: Yeah.I think it's important for a boy or for a man. *INV: That's all. Thank you.

\section{Conventions}

$\mathrm{RES}=$ researcher

$\mathrm{SUB}=$ subject

$\&=$ incomplete or unintelligible phonological string

$\mathrm{x}=$ unintelligible word with an unclear phonetic shape

$[/]=$ repetition

$[/ /]=$ rephrasing (repetition of main idea with some changes)

$[/ / /]=$ full reformulation

$+/ /=$ self-interruption

$@_{\mathrm{s}}=$ Spanish phrase 
$@$ ch = Chinese phrase

( ) = English translation of Chinese phrases 